\title{
COMPLIANCE OF INFECTION CONTROL PROTOCOL AMONG DENTISTS IN TRIVANDRUM CITY, KERALA, INDIA
}

\author{
Simy Mathew, Alexander M Luke \\ College of Dentistry, Ajman University, United Arab Emirates
}

\section{ARTICLE INFORMATION:}

Article History:

Received 17 April 2016

Accepted in revised form: 05 October 2016

Published:12 December 2016

Corresponding author: Simy Mathew

e-mail: s.mathew@ajman.ac.ae

Keywords: protocol, Infectious diseases.
Compliance, Dentists, Infection control

\begin{abstract}
ABSTRCAT:
Aim: Dentists are at a risk of transmitting infectious diseases in a dental setting, which may be transferred from the patient to dentist, dentist to patient or from patient to patient. There is risk of transmission of infectious agents via cross contamination through dental procedures. To assess the compliance to infection control protocol and assess the knowledge of infectious diseases among dentists in Trivandrum city. A descriptive cross sectional study was carried out among the dentists in Trivandrum city.

Materials and Methods: One hundred and seventy four dentists (males $56.7 \%$ ), who were members of the Indian Dental Association, Trivandrum Branch ( $80 \%$ of total dentists), were given self-administered questionnaires.

Analysis was done using SPSS version 14 .

Results: None of the respondents had $100 \%$ compliance to all infection control procedure. The mean score of compliance was 84.7/115 (86.3 - females and 83.5 - males, Range: 58-107). Mean score of knowledge of infectious diseases was 23.7/30 (23.6 - males and 23.8- females) 93\% compliance with standard protocol was the maximum reported ( 2 dentists). Experience of more than $30 \mathrm{yrs}$ and presence of a dental assistant was significantly associated with higher compliance to infection control protocol.

Conclusion: Being a dental college faculty, working in the private sector and awareness of standard protocol were significantly associated with Knowledge of infectious diseases. Compliance was positively correlated to knowledge. It is imperative from the study that dentists require more training and continuing dental education in infection control.
\end{abstract}

معلومات المقال

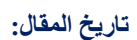

أستلم في:17 ابريل 2016 أبرال

قبل في : 05 اكتوبر 2017 بتريل 2016

نشر في: 12 ديسمبير 2016

المؤلف المسؤول:

سيمي ماثيو اليونيو

s.mathew@ajman.ac.ae: البريد الإلكترونيو

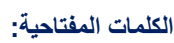

الامتثال، أطباء الالاسنان، بروتوكول التحكم في العدوى،

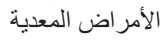

الملخص العربي:

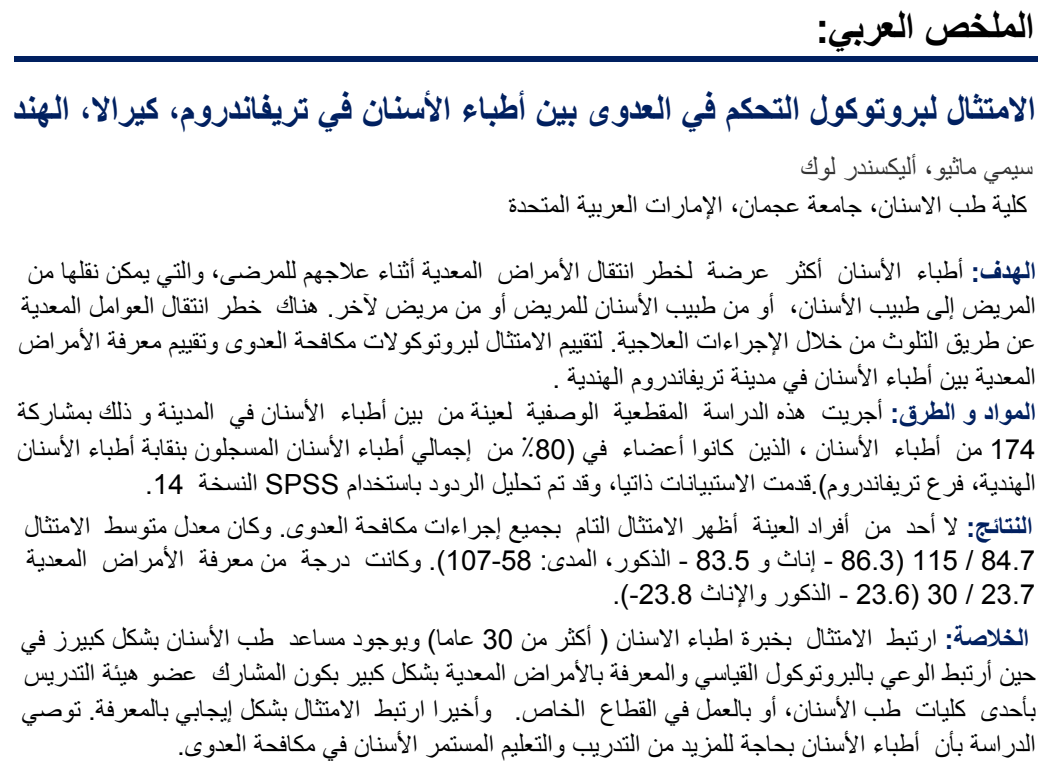

Copyright $\odot$ 2016. LDJ. This is an open access article distributed under the Creative Commons Attribution 3.0 License, which permits unrestricted use, distribution, and reproduction in any medium, provided the original work is properly cited.

Citation: Libyan Dent J 2016, 6: 26521461 - http://dx.doi.org/10.5542/LDJ.v6i0. 26521461 


\section{INTRODUCTION}

Infection control is an important part in the practice of health professionals. ${ }^{1}$ Dentists are at a risk of transmitting infectious diseases in a dental setting, which may be transferred from the patient to dentist, dentist to patient or from patient to patient. ${ }^{2}$ There is risk of transmission of infectious agents via cross contamination through dental procedures. Transmission of microorganisms can occur in the dental settings through contact with blood or other body fluids, contaminated objects, an infected person or inhalation of airborne microorganisms. ${ }^{3}$

Percutaneous injuries in the dental office are one of the main risk factors for the transmission of diseases like Hepatitis B (HBV), Hepatitis C (HCV) and Human Immunodeficiency virus (HIV). ${ }^{4,5} \mathrm{~A}$ study among dental professionals in Washington revealed that the injuries were mainly related with cleaning of instruments, recapping needles and administering of local anesthesia. ${ }^{6} \mathrm{~A}$ review of literature by John A. Molinari ${ }^{7}$ has concluded that dentists are at higher risk of certain infectious diseases in comparison with the general population; and that the modified infection control protocol recommended by CDC in 2003 would reduce the risk of transmission of infectious diseases in the dental scenario. Cross infection can be described as the transmission of infectious agents between the patients and the staff in a clinical environment. $^{2}$

The infection control scenario in India has not been one to show a consistent level of compliance. The various literature suggests that dental personnel and the dental students are not aware of a laid down protocol for infection control. ${ }^{8}$ Although there have been clear protocol from the Western countries, ${ }^{2}$ the Indian dental fraternity is far behind in terms of compliance to these policies. ${ }^{8}$ Literature suggests that training for dental personnel in infection control has to be undertaken as mandatory in order to attain effective compliance to infection control procedures. ${ }^{9}$ The need for infection control in health care is a globally accepted fact. With the advent of the number of infectious diseases, the need for infection control in the dental setting has become very necessary.

In light of the limited studies in India on general dental practitioners, and lack of studies in Kerala, this study aims to fill in this critical gap in research by aiming to study the infection control procedures followed by dentists in Kerala; their compliance to internationally accepted standard guidelines and to understand their knowledge and perceptions with regard to infectious disease transmission in dentistry and infection control procedures. The objectives of this research were :

- To assess level of compliance with infection control protocol among dentists in Trivandrum city and factors associated with it.

- To evaluate the knowledge of dentists with respect to infection control and factors associated with it.

- To assess knowledge among dentists of risks of transmission of diseases like HIV, Hepatitis, Herpes etc.

\section{MATERIALS AND METHODS}

Ethical approval was obtained from Research Ethics Committee of Sree Chithra Tirunal Institute of Medical Sciences and Technology, Trivandrum, Kerala. This was a cross sectional descriptive survey, which documented the practices, knowledge and compliance of dentists, in accordance with the guidelines prescribed by the Center for Disease Control, Atlanta in the Morbidity and Mortality Weekly Report, May 28, 1993/42, and updated further in the Morbidity and Mortality weekly Report, December 19, 2003 / 52(RR17);1-61.The cross sectional study was done among the dentists in Trivandrum city. The sampling frame included all those dentists (BDS or MDS) who were working in Trivandrum city. Only those registered with the Indian Dental Association, Trivandrum branch were included in the study. Dental graduates either with or without post graduate training who are registered with the IDA, Trivandrum branch and are willing to participate were the study objects. This included private practitioners, employees of dental clinics and hospitals and dental college faculty. Dentists were deemed to be compliant with infection control protocol if they carried out all of the procedures listed in Table 1.

The responses were 'never', rarely', 'sometimes', 'often' and 'routinely' were scored as '1', '2', '3', '4' and ' 5 ' respectively. Dichotomous responses like 'Yes' and 'No' were scored as ' 1 ' and ' 0 ' respectively. Knowledge was also scored similarly. Scores were 
categorized as compliant for responses ' 4 " and ' 5 ', while the rest were considered as non compliant; for the ease of analysis.
The data were entered into Epi Data Version 3.1 and exported to SPSS. The data were then cleaned, coded and analyzed using SPSS for windows version 18.

Table 1: Infection Control protocol to complied to.

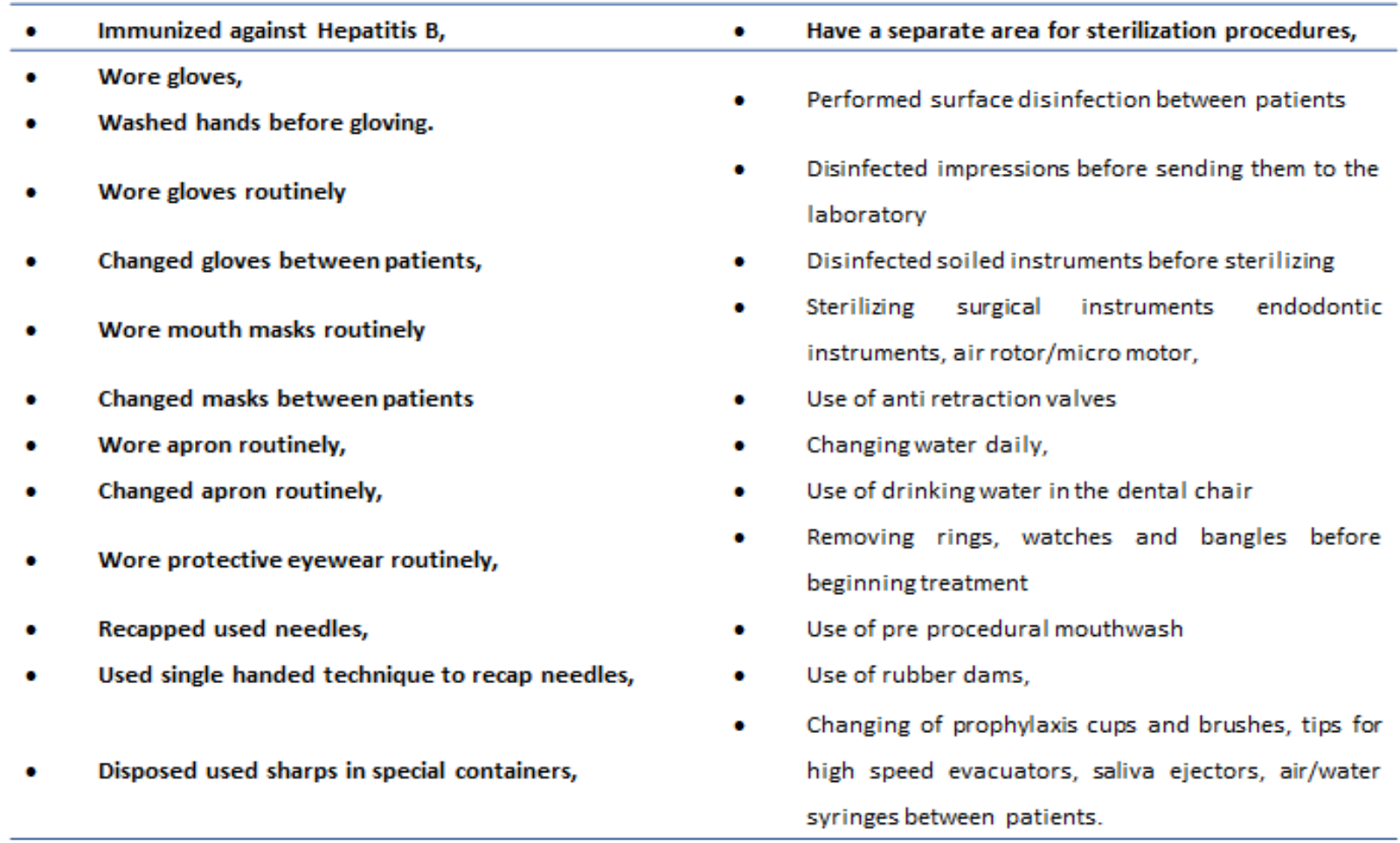

Dentists were deemed non-compliant if they did not adhere to any of the above procedures.

\section{RESULTS}

\section{Participant characteristics}

Out of the 174 dentists selected, 171(98.3\%) responded. The participants consisted of $97(56.7 \%)$ males and $74(43.3 \%)$ females. The age of the sample dentists ranged from 23 to 66 years (Mean $33.51 \mathrm{yrs}$, Standard deviation $=8.22$ ). The mean age for males was $34.35 \mathrm{yrs}$ and $32.41 \mathrm{yrs}$ for females. There were 91 dentists (53.2\%) without postgraduate training and 80 dentists $(46.8 \%)$ who had completed postgraduate training. $55 \%$ of the total sample had undergone undergraduate training in private institutions, while only $45 \%$ studied in government institutions. The number of patients attended to in a day ranged from 2 to 100 patients $($ Mean $=11.57$, Standard deviation $=12.38)$. The number of years of practice ranged from 1 to 43 years $($ Mean $=7.74$, Standard Deviation $=7.27$ ). The dentists in the sample worked over a range of 2 to 10 hours per day $($ Mean $=6.43$, Standard Deviation $=$ 1.91). The number of dental assistants for each dentist ranged from nil to 11 (Mean $=1.49$, Standard deviation $=1.6$ ). The demographic characteristics of the sample are presented in Table 2.

\section{Compliance to Infection Control Protocol}

The percentage of the participants who complied with the infection control protocol is described in Table 3.

\section{Personal Protective Equipment}

The use of gloves and mouth masks were reported more frequently than protective eyewear and apron/ coat $70.2 \%$ ( 120 dentists) reported to use disposable gloves, $14 \%$ ( 24 dentists) used sterile surgical gloves and $15.8 \%$ (27 dentists) used both disposable and sterile surgical gloves depending on the case. Thirtynine dentists $(22.8 \%)$ reported to use soap for washing 
Table 2: Demographic characteristics.

\begin{tabular}{|c|c|}
\hline Variable & No (\%) of participants \\
\hline \multicolumn{2}{|l|}{ Age } \\
\hline 23 to 35 years & $67.3 \%$ \\
\hline 36 to 45 years & $25.7 \%$ \\
\hline 45 and above & $7.0 \%$ \\
\hline \multicolumn{2}{|l|}{ Sex } \\
\hline Male & $56.7 \%$ \\
\hline Female & $43.3 \%$ \\
\hline \multicolumn{2}{|l|}{ Qualification } \\
\hline General Dentist & $53.2 \%$ \\
\hline Specialist & $46.8 \%$ \\
\hline \multicolumn{2}{|l|}{ Occupation } \\
\hline Private practice & $32.2 \%$ \\
\hline Government Dental College Faculty & $31.6 \%$ \\
\hline Private Dental College Faculty & $19.3 \%$ \\
\hline Private Hospital & $14 \%$ \\
\hline Public Hospital & $2.9 \%$ \\
\hline \multicolumn{2}{|c|}{ Type of college in which general dentistry was completed } \\
\hline Private & $55 \%$ \\
\hline Government & $45 \%$ \\
\hline \multicolumn{2}{|c|}{ Type of college in which specialization was completed } \\
\hline Private & $26.3 \%$ \\
\hline Government & $73.8 \%$ \\
\hline \multicolumn{2}{|l|}{ Field of Specialization } \\
\hline General Dentistry & $39.8 \%$ \\
\hline Endodontics & $15.2 \%$ \\
\hline Prosthodontics & $9.9 \%$ \\
\hline Orthodontics & $8.2 \%$ \\
\hline Oral Surgery & $8.2 \%$ \\
\hline Pedodontics & $7.0 \%$ \\
\hline Periodontics & $4.7 \%$ \\
\hline Oral Pathology & $2.3 \%$ \\
\hline Oral Medicine and Radiology & $3.5 \%$ \\
\hline Community/Public Health Dentistry & $1.2 \%$ \\
\hline \multicolumn{2}{|l|}{ No. of hours working per day } \\
\hline 1 to 3 hours & $7.0 \%$ \\
\hline 4 to 6 hours & $45.6 \%$ \\
\hline More than 7 hours & $47.4 \%$ \\
\hline \multicolumn{2}{|l|}{ Average no. of patients per day } \\
\hline 1 to 10 & $69.6 \%$ \\
\hline 11 to 20 & $23.4 \%$ \\
\hline More than 20 & $7.0 \%$ \\
\hline \multicolumn{2}{|l|}{ No. of years in practice } \\
\hline 1 to 10 years & $49.1 \%$ \\
\hline 11 to 20 years & 24.0 \\
\hline 21 to 30 years & 15.8 \\
\hline More than 30 years & 11.1 \\
\hline \multicolumn{2}{|l|}{ No. of dental assistants } \\
\hline Nil & 26.9 \\
\hline 1 to 5 & 70.2 \\
\hline More than 5 & 2.9 \\
\hline
\end{tabular}


Table 3: Infection Control Protocol

\begin{tabular}{|c|c|}
\hline Infection Control Procedure & $\begin{array}{l}\text { No of participants who followed the } \\
\text { procedure (\%) }\end{array}$ \\
\hline Vaccination against Hepatitis B & $90.1 \%^{*}$ \\
\hline No & $9.9 \%$ \\
\hline One dose & $2.9 \%$ \\
\hline Two doses & $10.5 \%$ \\
\hline Three doses & $76.6 \%$ \\
\hline $\begin{array}{l}\text { ( }{ }^{*} \text { includes those having taken vaccination regardless of } \\
\text { completion) }\end{array}$ & \\
\hline \multicolumn{2}{|l|}{$\begin{array}{l}\text { PERSONAL PROTECTIVE EQUIPMENT } \\
\text { Gloves }\end{array}$} \\
\hline Routinely washing hands before gloving & $71.9 \%$ \\
\hline Wearing Routinely & $98.8 \%$ \\
\hline Changing between patients routinely & $94.2 \%$ \\
\hline \multicolumn{2}{|l|}{ Mouth masks } \\
\hline Wearing Routinely & $98.2 \%$ \\
\hline Changing between patients routinely & $29.2 \%$ \\
\hline \multicolumn{2}{|l|}{ Apron/Coat } \\
\hline Wearing routinely & $60.8 \%$ \\
\hline Changing regularly & $19.9 \%$ \\
\hline Using protective eyewear routinely & $25.7 \%$ \\
\hline \multicolumn{2}{|l|}{ NEEDLE SAFETY } \\
\hline Needle recap & $93.6 \%$ \\
\hline Single handed recap technique & $67.3 \%$ \\
\hline Special container for disposal of sharps & $31 \%$ \\
\hline \multicolumn{2}{|l|}{ STERILISATION AND DISINFECTION } \\
\hline Separate area for sterilization & $87.1 \%$ \\
\hline Surface Disinfection routinely & $64.9 \%$ \\
\hline Disinfection of impressions & $42.1 \%$ \\
\hline Disinfection of soiled instruments & $100 \%$ \\
\hline \multicolumn{2}{|l|}{ Surgical Instruments } \\
\hline Autoclaving & $87.1 \%$ \\
\hline \multicolumn{2}{|l|}{ Endodontic Instruments } \\
\hline Glass bead sterilizer & $47.4 \%$ \\
\hline Autoclaving & $28.1 \%$ \\
\hline \multicolumn{2}{|l|}{ Airrotor/Micromotor } \\
\hline Sterilize between patients & $54.4 \%$ \\
\hline Autoclaving & $31.6 \%$ \\
\hline \multicolumn{2}{|l|}{ WATER QUALITY } \\
\hline Use of Antiretraction valves & $15.8 \%$ \\
\hline Changing water daily & $58.5 \%$ \\
\hline Use of drinking water & $28.1 \%$ \\
\hline \multicolumn{2}{|l|}{ SPECIAL CONSIDERATIONS } \\
\hline Remove rings/watches/bangles & $68.4 \%$ \\
\hline Use of pre procedural mouthwash & $25.1 \%$ \\
\hline Use of rubber dams & $2.3 \%$ \\
\hline \multicolumn{2}{|l|}{ Change for each patient } \\
\hline Prophylaxis cups and brushes & $84.8 \%$ \\
\hline Tips for high speed evacuators & $88.9 \%$ \\
\hline Saliva ejectors & $90.6 \%$ \\
\hline Air/Water syringes & $40.9 \%$ \\
\hline
\end{tabular}


of hands before donning gloves, 111 dentists $(64.1 \%)$ used disinfecting solution and 20 dentists $(11.7 \%)$ used both soap and disinfecting solution. Two dentists reported that they never changed gloves between patients. Four dentists reported that they used the same pair of gloves for patients attended to in a session and that the gloves were changed only at the end of each session (2 pairs of gloves a day). Twelve dentists reported that they do not use apron/coat while treating patients. Thirty dentists never used protective eyewear during dental procedures.

\section{Sterilization and Disinfection}

One hundred and forty nine dentists (87.1\%) reported the presence of a separate area for sterilization procedures. One hundred and fifty seven dentists $(91.8 \%)$ regularly asked the patients about their medical history before commencement of treatment, while 14 dentists $(8.2 \%)$ did so only if they doubted the medical status of the patient.

Surface disinfection was done routinely by $64.9 \%$ (111 dentists). Only one dentist reported of not following surface disinfection procedures. Alcohol was the most frequently used surface disinfectant $(60.8 \%)$, followed by ammonium compounds $(15.2 \%)$, phenolics $(10.5 \%)$, sodium hypochlorite (7.6\%) and iodophors (5.8\%).

Autoclaving of surgical instruments was reported by $87.1 \%$, while $17 \%$ used boiling water and $3 \%$ used other methods. For the sterilization of endodontic files, glass bead sterilizer was used by $47.4 \%$ and autoclave by $28.1 \%$. Alcohol was most commonly used to sterilize the rotary instruments between patients $(52 \%)$ while autoclaving was followed by $31.6 \%$. Only $54.4 \%$ of dentists sterilized the rotary instruments between patients.

\section{Needle Safety}

One hundred and sixty nine dentists $(98.8 \%)$ used single use disposable syringes. Ten dentists $(5.8 \%)$ did not recap the needle after administering local anesthesia. One hundred dentists (58.5\%) reported having experienced needle injury in their practice. Of these, $55 \%$ have experienced needle injury once, $20 \%$ twice, $7 \%$ thrice and $12 \%$ more than thrice in the past year. Six percent reported to have experienced needle injury in previous years of practice.

\section{Water Safety}

Eighty-eight dentists (51.5\%) reported that they were aware of anti retraction valves but only 27 dentists $(15.8 \%)$ used them in their practice. Only 48 dentists $(28.1 \%)$ reported the use of potable water in the dental unit, while $15.2 \%$ used the corporation water and $56.7 \%$ used water stored in tanks.

\section{Special Considerations}

Eleven dentists (6.4\%) never removed their watches/ rings/bangles before commencing treatment procedure. Before dental treatment, $9.4 \%$ never used pre procedural mouthwash. $52.6 \%$ never used rubber dams in their practice.

\section{Knowledge of Standard Infection Control Protocol}

Only $29.2 \%$ ( 50 dentists) reported having knowledge of any standard infection control protocol. 2.3\% reported to know of the $\mathrm{CDC}$ protocol, $9.4 \%$ knew of the OSHA protocol, $7 \%$ were aware of both the CDC and OSHA protocol and $9.4 \%$ knew of other protocol.

Table 4 and 5 show the knowledge of standard infection control protocol. The mean score of compliance in the sample was 84.7 (Range 58 to 107). Mean score of compliance among males and females was 83.5 and 86.2 respectively. The mean score of compliance among general dentists and specialists was 86.4 and 82.9. Since scoring was done to assess the level of compliance and a wide range was obtained, tests for normality were done. This gave a ' $p$ ' value of 0.514 (Shapiro- Wilk), which is statistically insignificant. Therefore, it was concluded that the distributions were not different from the normal distribution and parametric tests assuming normality were performed to test association of variables with compliance. No dentist in the sample was completely compliant with all the procedures of infection control as per the CDC guidelines. The maximum score of compliance obtained was 107 out of 115 (2 dentists, $93 \%$ compliance). 
Table 4: Bivariate Analysis: Demographic factors and compliance with Infection control protocol

\begin{tabular}{|c|c|c|c|}
\hline Variable & $\begin{array}{c}\text { Total } \\
(n=171)\end{array}$ & $\begin{array}{l}\text { Compliance } \\
\text { (mean score) }\end{array}$ & $\begin{array}{c}\text { t test } \\
\text { p value }\end{array}$ \\
\hline \multicolumn{4}{|l|}{ Sex } \\
\hline Male & 97 & 83.5 & 0.05 \\
\hline Female & 74 & 86.3 & \\
\hline \multicolumn{4}{|l|}{ Qualification } \\
\hline General Dentistry & 91 & 86.3 & 0.018 \\
\hline Specialty Dentistry & 80 & 82.8 & \\
\hline \multicolumn{4}{|c|}{$\begin{array}{l}\text { Type of college in which General Dentistry was } \\
\text { completed }\end{array}$} \\
\hline Private & 94 & 86.2 & 0.027 \\
\hline Government & 77 & 82.9 & \\
\hline \multicolumn{4}{|c|}{$\begin{array}{l}\text { Type of college in which specialization was } \\
\text { completed }\end{array}$} \\
\hline Private & 21 & 87.3 & 0.024 \\
\hline Government & 59 & 81.3 & \\
\hline \multicolumn{4}{|l|}{ Type of practice } \\
\hline General practice & 68 & 87.8 & 0.001 \\
\hline Specialty practice & 103 & 82.7 & \\
\hline \multicolumn{4}{|l|}{ Employment sector } \\
\hline Private sector & 112 & 86 & 0.017 \\
\hline Government sector & 59 & 82.3 & \\
\hline \multicolumn{4}{|c|}{ College faculty versus private practice } \\
\hline Dental college faculty & 84 & 87.5 & \\
\hline Private practice & 87 & 82.0 & 0.000 \\
\hline
\end{tabular}

Table 5: Bivariate Analysis: Demographic Factors and Compliance with Infection Control Protocol

\begin{tabular}{|c|c|c|c|}
\hline Variable & $\begin{array}{c}\text { Total } \\
(n=171)\end{array}$ & $\begin{array}{l}\text { Compliance } \\
\text { (mean score) }\end{array}$ & $\begin{array}{l}\text { ANOVA } \\
\text { p value }\end{array}$ \\
\hline \multicolumn{4}{|l|}{ No. of patients } \\
\hline Less than 10 & 119 & 83.9 & 0.176 (not significant) \\
\hline 11 to 25 & 43 & 86.2 & \\
\hline More than 25 & 9 & 88.8 & \\
\hline \multicolumn{4}{|c|}{ No. of hours working per day } \\
\hline Less than $5 \mathrm{hrs}$ & 33 & 81.4 & 0.05 \\
\hline 5 to $8 \mathrm{hrs}$ & 121 & 85.2 & \\
\hline More than $8 \mathrm{hrs}$ & 17 & 87.8 & \\
\hline \multicolumn{4}{|l|}{ Years of experience } \\
\hline 1 to $10 \mathrm{yrs}$ & 125 & 83 & 0.002 \\
\hline 11 to $20 \mathrm{yrs}$ & 37 & 89.4 & \\
\hline 21 to $30 \mathrm{yrs}$ & 5 & 89.2 & \\
\hline More than $30 \mathrm{yrs}$ & 4 & 89 & \\
\hline \multicolumn{4}{|l|}{ Number of dental assistants } \\
\hline No assistants & 46 & 78.8 & 0.000 \\
\hline 1 to 5 assistants & 120 & 86.7 & \\
\hline More than 5 assistants & 5 & 91.4 & \\
\hline \multicolumn{4}{|l|}{ Age groups } \\
\hline Up to $35 y r s$ & 114 & 83.6 & 0.074 (not significant) \\
\hline 36 to 45 yrs & 44 & 86.8 & \\
\hline More than $45 \mathrm{yrs}$ & 12 & 88.5 & \\
\hline \multicolumn{4}{|c|}{ Patient load(no. of patients per hour) } \\
\hline 1 patient & 62 & 83.5 & 0.432 (not significant) \\
\hline 2 to 3 patients & 87 & 85.6 & \\
\hline More than 3 patients & 22 & 84.6 & \\
\hline
\end{tabular}


Correlation was performed between the variables 'compliance' and 'knowledge'. They were found to be positively correlated (Spearman Rho Rank correlation coefficient $=0.20, p=0.009$ ). Therefore, it can be concluded that compliance improved if knowledge was increased.

\section{Multivariate analysis (logistic regression)}

The knowledge score was dichotomized using 75th percentile to be taken as the dependent variable. Multivariate analysis was done using logistic regression. Variables having ' $p$ ' value of less than 0.2 were considered for multivariate analysis. The variables included in the logistic regressions were: awareness of standard infection control protocol, employment sector, type of practice and being a dental college faculty versus private practice.

\section{DISCUSSION}

In the sample surveyed, none of the dentists complied $100 \%$ with all the procedures described in the standard protocol. This may be due to the lack of knowledge among dentists of the standard protocol that is to be followed. Only 50 dentists $(29.2 \%)$ were aware of the standard infection control protocol. This was much lesser than that reported in Valcea, Romania. ${ }^{10}$

Almost all the dentists in used gloves and mouth masks routinely (99\%and $98 \%$ respectively). This is much higher than that reported in Pakistan ${ }^{11}$ and similar to studies performed in Canada ${ }^{12}$ and Italy. ${ }^{13}$ Changing of gloves between patients (94\%) was practiced more often in this study than in Haryana. ${ }^{14}$ Changing of mouth masks for each patient was routinely practiced by only $30 \%$ of dentists. This was much lower than the Canadian ${ }^{12}$ and Jordanian ${ }^{15}$ studies. More than half of the dentists used apron on regular practice, which was in tandem with the Jordanian study. ${ }^{15}$ Routine use of eyewear was reported by $26 \%$, which was higher than that in Sudan ${ }^{16}$ and Haryana. ${ }^{14}$

More than $90 \%$ of dentists recapped needles after use. Of these, more than $65 \%$ used single-handed recap technique. Although this was less than that reported in the US Air Force dental clinics, it was higher than that reported in Haryana. ${ }^{14}$ Only 31 percent of dentists used special puncture resistant containers for the disposal of sharps. This was higher than that used in Pakistan. ${ }^{11}$ Almost all dentists used disposable syringes for administering local anesthesia. This was in par with studies from Malaysia ${ }^{17}$ and Haryana. ${ }^{14}$

Needle injury was reported by almost 60 percent of the dentists in the past one year, but there was no information regarding post exposure prophylaxis. This was less than that reported in the Romanian study ${ }^{10}$ but more than that reported in Durban ${ }^{18}$ and South Africa. ${ }^{19}$ Three doses of Hepatitis B vaccination was completed by more than 75 percent which was higher than in dentists in Haryana, ${ }^{14}$ Pakistan $^{11}$ and Thailand, ${ }^{20}$ but much lesser than Canadian ${ }^{12}$ and Scottish ${ }^{21}$ dentists were.

Autoclaves were used in more than 85 percent of the practices for the sterilization of dental instruments, which was in tandem with studies from United Kingdom $^{22}$ and Scotland. ${ }^{21}$ The use of autoclaves among dentists in Trivandrum was considerably higher than that among dentists in Haryana. ${ }^{14}$ Almost 60 percent of the dentists reported to sterilize dental impressions before sending to the laboratory, which was similar to that reported in Durban ${ }^{18}$ and higher than that reported by dentists in Italy. ${ }^{13}$ Use of rubber dams was reported to be only in 2.3 percent, which was much lesser than that reported in Canada, ${ }^{12}$ Western Cape ${ }^{23}$ and Durban. ${ }^{18}$

Compliance to infection control protocol was higher in the private sector. This was in accordance to literature. $^{20}$ Dental college faculties were more compliant with infection control protocol. This may be because of the constant exposure of dental college faculty to theory of dental practice and infection control in contrast to those in private practice. Conversely, there was poor compliance among dental school students of the final years of study. ${ }^{23-25}$

In this study, it was noted that the general practitioners were more compliant with infection control protocol in comparison to specialists. This suggests that postgraduate education does not add to the compliance levels. The data collected shows that the average number of patients for specialists is higher than that for general dentists. Although, the patient load was not significant in this study for compliance, it could be a factor that influenced lower levels of 
compliance among specialists. None of the previous studies documented the presence and number of dental assistants. The presence of dental assistants in dental clinics was significantly associated with compliance levels. Dental assistants perform the infection control procedures when they are present. This brings about more regularity in the performance of infection control. Compliance levels were dependent on knowledge levels and as knowledge was higher in the private sector, compliance was higher in private sector. Literature from Chennai opposes this finding, as the knowledge in the private sector dental clinic was inadequate in the sample. ${ }^{26}$ The lack of compliance in the government sector could be due to the heavy load of patients in government hospitals and dental colleges. In addition, literature suggests that expenditure on infection control creates a gap in compliance to infection control procedures. ${ }^{8}$ As the government sector depends on funding from the government, there could be a lack of infection control materials, which could be the reason for lower compliance levels.

The publication of a protocol for infection control among oral health care workers by the Dental Council of India has emphasized on the priority of compliance to practices to prevent and control contamination and cross infection. ${ }^{27}$ Yet the role of the national, state and local agencies to ensure the adherence has to be reexamined and reinforced. Therefore, from this study, it is evident that not all infection control procedures are complied with in the dental practice in Trivandrum city.

\section{CONCLUSION}

In conclusion, the findings of this study highlight the need for strict adherence to infection control protocol in dentists. Evidence has suggested that infection control procedures can reduce the risk of disease transmission by compliance to standard infection control protocol.

This study shows that there is regularity of compliance to certain procedures like use of personal protective equipment etc., but a gap lays in the use of single use disposable items. The need to incorporate infection control as a mandatory part of dental curriculum has been stressed in this study.

There is need to increase the knowledge among dental professionals on the risks and routes of disease transmission in the dental office. In addition, very few dentists were aware of the standard protocol to be adhered to in dental practice for infection control. There needs to be standards set by the local, state and national dental associations with regard to standard procedures to be followed.

\section{REFERENCES}

1. Wenzel RP. The Lowbury lecture. The economics of nosocomial infections. Journal of Hospital Infection. 1995; 31:79-87.

2. Centers for Disease Control and Prevention. Recommended infection control practices in dentistry. MMWR Recommendations and Reports 1993; 42(RR-8):1-12. Available at: www.cdc.gov/mmwr/previewmmwrhtml/00021095.htm. Accessed on February 17, 2013.

3. Bolyard EA, Tablan OC, Williams WW, Pearson ML, Shapiro CN, Deitchman SD, Hospital Infection Control Practices Advisory Committee. Guideline for infection control in health care personnel. American Journal of Infection Control. 1998;26:289--354.

4. Sulkowski MS, Ray SC, Thomas DL. Needlestick Transmission of Hepatitis C. JAMA 2002, 287:2406-2413.

5. Sepkowitz KA. Occupationally acquired infections in health care workers Part 2. Ann Intern Med 1996, 125:917- 928.

6. Percutaneous injuries among dental professionals in Washington State Syed M Shah, Anwar T Merchant and James A Dosman. BMC Public Health 2006, 6:269.

7. John A Molinari. Infection control: Its evolution to the current standard precautions. Journal of American Dental Association. 2003; 134(5): 569-574.

8. Puttaiah R, Shetty S, Bedi R, Verma M. Dental infection control in India at the turn of the century. World Journal of Dentistry 2010; 1(1): 1-6.

9. Jawdekar AM. Infection Control Policy for Dental Practice: An Evidence based Approach. J ContempDent 2013;3(2):82-86 
10. Duffy RE, Cleveland JL, Hutin YJ, Cardo D. Evaluating Infection Control Practices Among Dentists In Vâlcea, Romania, In 1998. Infection Control and Hospital Epidemiology 2004;25:570-575.

11. Kishore J, Goel P, Sagar B, Joshi TK. Awareness about biomedical waste management and infection control among dentists of a teaching hospital in New Delhi, India.Indian J Dent Res. 2000; 11(4):157-61.

12. Gillian M. McCarthy,John J. Koval,Michael A. John, John K. MacDonald. Infection Control Practices Across Canada: Do Dentists Follow the Recommendations?. Journal of Canadian Dental Association 1999; 65:506-11.

13. Veronesi L, Bonanini M, Dall'Aglio P, Pizzi S, Manfiedi M, Tanzi ML. Health hazard evaluation in private dental practices: a survey in a province of northern Italy. Acta Biomedica de L'Ateneo Parmense: organo della Societa de Medicina e scienza naturali de Parma. 2004;75(1):50-55.

14. Al-Omari MA Al-Dwairi ZN. Compliance with Infection Control Programs in Private Dental Clinics in Jordan. Journal of Dental Education 2005; 69: 693-698.

15. Puttaiah R, Bedi R, Almas K. A survey of infection control practices among general Dental Practitioners in Lahore, Pakistan. Journal of the Pakistan Dental Association 2001; 10:71-6.

16. Razak IA, Lind OP. Cross-infection control in Malaysian dental practice. Singapore Dent J. 1995; 20: 11-5.

17. Yengopal V, Naidoo S, Chikte UM. Infection control among dentists in private practice in Durban. South African Dental Journal. $2001 ; 56: 580-4$.

18. Al Bagieh HN. Cross-Infection Control Practice of Staff in a Dental School. OdontoStomatologie Tropicale 1997;20:25-28.

19. Leggat PA, Chowanadisai S, Kukiattrakoon B, Yapong B, Kedjarune U. Occupational hygiene practices of dentists in southern Thailand. Int Dent J. 2001; 51: 11-16.
20. Gore SM, Felix DH, Bird AG, Wray D. Occupational risk and precautions related to HIV infection among dentists in the Lothian region of Scotland. The Journal of Infection. 1994; 28: 209-22.

21. Scully C, Blake C, Griffiths M, Levers H. Protective wear and instrument sterilization/ disinfection in UK general dental practice. Health Trends. 1994;26:21-2.

22. Naidoo S,. Mahommed A. Knowledge, attitudes, behaviour and prevalence of TB infection among dentists in the Western Cape. SADJ 2002;57: 476-478.

23. Singh A, Purohit BM, Bhambal A, Saxena S, Singh A, Gupta A. Knowledge, attitudes, and practice regarding infection control measures among dental students in Central India. J Dent Educ. 2011;75(3):421-7.

24. Rahman B, Abraham SB, Alsalami AM, Alkhaja FE, and Najem SI. Attitudes and practices of infection control among senior dental students at college of dentistry, university of Sharjah in the United Arab Emirates. Eur J Dent. 2013; 7(Suppl 1): S15-S19.

25. Kumar $S$, Sharma J, Duraiswamy $P$, Kulkarni S. Infection control practices among undergraduate students from a private dental school in India. Rev. odonto ciênc. 2009;24(2):124-128.

26. Gopal KS, Jesija JS, Harsha Vardhan BG. Cross infection and sterilizationmethods: $A$ survey among dental practionersin Chennai. Int J Contemp Dent Med Rev. 2014, Article ID 081114, 2014.doi: 10.15713/ins.ijcdmr.10.

27. Kohli A, Puttiah R. Dental Infection Control \& Occupational Safety Dental Infection Control \& Occupational Safety For Oral Health Professionals. Dental council of India. Available at https://c.ymcdn.com/sites/osap.site-ym.com/ resource/resmgr/DocsIndia_Infectioncontrolbook 2.pdf. Accessed on 2.3.2016. 